\title{
EMPLOYEES ENGAGEMENT IN SELF DEVELOPMENT ACTIONS FOLLOWING LEADERSHIP DEVELOPMENT PROGRAMS
}

\section{Manuel Urban}

Mg. rer. soc. oec

\begin{abstract}
Organisational leadership development initiatives are continuously growing because many companies have understood that to be able to be competitive in this fastchanging economic environment, they have to train their workforce constantly. Today leadership development is a multi-billion-dollar industry where many institutions promise to increase knowledge and effectiveness of managers and leaders. Very often these programs are initiated by the organisation itself. Unfortunately, still, many employees have not understood that constant learning will be the main key to future success in their professional life. Of course, organisational interventions are needed, but research indicates that stimulating participants to take development actions on their own is far more promising for successful leadership development. It is the high number of leadership development initiatives with no or only limited results that have led to this research. This study aimed to investigate the influence of feedback following an organisational leadership development initiative on participants' likelihood to take personal development actions. To achieve this, a new approach to feedback was introduced analysing the reaction, as well as the perceived accuracy and usefulness of delivered feedback for participants and the potential engagement in self-development activities. This research suggests that after a leadership development program which is followed by personalised feedback, additional organisational actions can be helpful to understand how to increase the chances of a successful leadership development program where participants engage in self-development actions. Knowing how participants react and how useful and accurate they perceive feedback is helping organisations to focus on employees that need more attention than others in the process to start development actions on their own.
\end{abstract}

Keywords: Leadership development; 360-degree feedback; Self-development; Learning organisation

\section{Introduction}

The development of leadership capabilities is a prime task for organisations. Globalisation, an increasingly diverse workforce, and the millennials with different views and expectations then prior generations entering organisations makes it necessary to develop more and better leaders. To tackle the increasing tasks leaders have to fulfil many initiatives in organisations 
are targeting the development of leadership capabilities through leadership development programs. Surprisingly, in comparison to leadership theory, with over a century of research, the leadership development literature is rather short. Therefore, more factors influencing the success of leadership development initiatives must be found, and their impact has to be evaluated. Considering the resources organisations put in the development of their leaders, and the fact that many leadership development programs fail, clearly indicate the need for further investigation in this research area. Many of the existing leadership development programs value and use 360-degree feedback as a cornerstone to their initiatives. This kind of feedback has shown promising results due to the possibility to give leader feedback from different angles and show him the difference in his self- and others' rating. Unfortunately, the problem is that despite great efforts, many leadership development programs fail. Brett and Atwater (2001) state that "a better understanding of the emotional and cognitive reactions is needed" if participants should benefit from the feedback process and organisations want to retrieve their investment (p. 941). Leadership development is seen to be an initiation to leaders self-development, but organisational actions can facilitate or reduce the probability that participants engage in selfdevelopment activities (Boyce, Zaccaro, \& Wisecarver, 2010). In other words, it is the intrapersonal and the interpersonal processes that are central to leadership development over time (Day, Fleenor, Atwater, Sturm, \& McKee, 2014). On an individual level, only limited research has been done to understand the characteristics that are associated with how individuals engage in self-development activities to develop their leadership skills (Boyce, Zaccaro, \& Wisecarver, 2010).

This article aims to provide further insight on managers' reaction towards feedback especially regarding positive or negative reactions, the perceived usefulness, and accuracy of provided feedback and the implications these variables have on the likelihood to take selfdevelopment actions. Since the underlying leadership development in this study was utilising a 360-degree feedback process, it was also investigated whether the differences between self- and others affected the likelihood that self-development actions are taken.

Leadership development initiatives, with focus on both, task-oriented and relationship-oriented leadership, have shown significant impact on positive outcomes such as performance, task achievement, and commitment. Nevertheless, not all leadership development initiatives are equally successful. Studies outline the importance of feedback following leadership development initiatives arguing that the reaction towards feedback may vary due to the type and form of feedback given. Furthermore, how recipients of feedback accept it and perceive it as being useful may influence the way how they react to the feedback. Although organisations 
very often provide support following a leadership development program, it is the attitude of each individual that has been shown to have an even greater influence on the final results. This study adds knowledge through empirical data on the relevance of feedback in leadership development initiatives utilising multirater (incorporating self- and others-rating) tools for developing their leaders.

\section{Leadership theory versus leader and leadership development theories}

The history of leadership theory with over a century of research is relatively long, whereas the literature on leadership development is rather short (Day et al., 2014). In contrast to leader and leadership development, leadership theory is building the foundation and basic assumptions of leadership approaches that help them to be most effective. It is a misperception to think that developing individual leaders and effective leadership processes is simply depending on choosing the right leadership theory and training people to apply those theories (Day et al., 2014). One of the critics of leadership studies is that due to a large number of different leadership theories also many forms of leadership development programs have been introduced and marketed but their effectiveness has not been tested adequately (Goethals, Sorenson, \& Burns, 2004).

It is important to distinguish leadership theory from theories regarding leader (intrapersonal focus) and leadership (interpersonal focus) development. The focus of leader development is put on the development of individual leaders, whereas leadership development is focusing on development processes that primarily involve multiple individuals and the enhancement of leadership capacity. It is therefore argued that leader development is one aspect of the broader process of leadership development (Van Velsor, McCauley, \& Ruderman, 2010). Leader development can be defined "as the expansion of a persons' capacity to be effective in leadership roles and processes" (Van Velsor et al., 2010, p. 2) It focuses on increasing human capital through the development of individual knowledge, skills, and abilities, assuming that effective leadership occurs through the development of individual leaders. In contrast, leadership development is defined by Van Velsor et al. (2010) as "the expansion of a collective's capacity to produce direction, alignment, and commitment" (p. 20). Leadership development focuses on building networked relationships among individuals in an organisation. Other authors define leadership development as "every form of growth or stage of development in the life cycle that promotes, encourages, and assists the expansion of knowledge and expertise required to optimise one's leadership potential and performance" (Brungardt, 1997, p. 86). For this study, the theoretical 
differences of the terms leadership development and leader development are acknowledged, but the term leadership development is used to include both perspectives and approaches.

\section{Leadership development programs in organisations}

Leadership development is a multi-billion-dollar industry and one of the most expensive activities in corporate training budgets. On a global scale, it is estimated that companies spend annually more than USD 60 billion for leadership development initiatives, USD 14 billion alone in the US market (Gurdjian, Halbeisen, \& Lane, 2014). Spending on leadership development has been increased significantly in recent years and is predicted to rise further. Also in Austria on average USD 2000 11000 are spent per participant to enhance their leadership competencies (Krims, 2016). Organisations are investing heavily on the development of their leaders, especially with millennials becoming the biggest group of employees in the business environment. In a global study carried out by PwC (PricewaterhouseCoopers) 1.409 CEOs where asked what aspects of their talent strategy are being changed to have the most significant impact on attracting, retaining and engaging people to remain relevant and competitive. With 72 percent of these CEOs were concerned about the availability of talent, 49 percent said that their primary talent strategy would focus on the development of their leader pipeline (PWC, 2016). Considering these talent strategies and the massive investments of organisations and individuals in leadership development programs, it seems surprising that only limited research on the effectiveness of these programs exists (Ely et al., 2010).

An ongoing discussion in this context is, whether leaders are born or made, in other words, if leadership capabilities can be taught. Today, there seems to be consensus on the fact that although some cognitive abilities and personality traits are innate and remain stable over time, there are many human capabilities that can be developed and trained to enable individuals to perform their tasks in a better way (Van Velsor et al., 2010). Burke and Day (1986) conducted a meta-analysis that is commonly regarded as the principal empirical support for the effectiveness of managerial training and leadership development programs. Their meta-analysis included seventy published and unpublished business studies over thirty years in different industries and companies. Those studies involved managerial or supervisory personnel, where more than one training program has been evaluated and included at least one control or comparison group. Burke and Day found that managerial training was moderately effective and provided true mean effect sizes for each of the four criterion-measure categories used. Those where, subjective learning (.34), objective learning 
(.38), subjective behaviour (.49), and objective results (.67). Approximately twenty years later, Collins \& Holton (2004) conducted another metaanalysis, integrating eighty-three studies to determine the effectiveness of leadership development initiatives in their enhancement of performance, knowledge, and expertise at an individual, team and organisational level. They concluded that if sufficient front-end analysis is conducted to assure that the right development is offered to the right leaders, organisations should feel comfortable that their leadership development programs will produce significant results and participants can gain substantial improvements in both knowledge and skills.

Unfortunately, although the focus of research during the last century was lying on leadership theory, the development of these capabilities was getting far less attention. Leadership is an emerging interdisciplinary field, but there has been very little research on leadership development programs in general (Avolio, Avey, \& Quisenberry, 2010). Day et al. (2014, p. 64) state that "we need to focus on development as much as leadership to shed light on how this process unfolds." This is particularly important since research findings suggest that not even can managerial leadership development do not affect, but the experience that participants have can become negative. It is therefore crucial of providers of leadership development programs to understand that merely identifying and placing individuals in these programs do not ensure that they will become more effective leaders when completing the training (Kirchner \& Akdere, 2014). Arnulf, Glas $\emptyset$, Andreassen, \& Martinsen (2016) investigated the perception of leadership development program participants toward the outcome of training initiatives with the consequence that more than half of participants were negatively biased toward the field and experienced the activities as negative but harmless, and 44 percent as even negative. As the cause of negative experiences was most frequently attributed to external consultants, operating in an environment characterised by a lack of evaluation. Further, it is argued that the most likely scenario for negative effects seems to occur in companies that invest quite a lot in the development activities themselves, but not in their evaluation. In contrary companies, that either invests little and rely on internal resources or invest high sums of money for certain leadership development and therefore also monitor the effects closely achieve the most favourable outcome. Arnulf et al. (2016) argue that leadership development activities are having negative consequences if they directly reduce the person's capacity to perform leadership roles or indirectly reduce organisational performance by wasting resources and undermining the belief in developmental efforts. Based on their research, Kirchner \& Akdere (2014) argue that there is a significant probability, that if someone is participating in leadership development programs against their wishes, they will not fully engage in the themes 
being discussed. Since organisations typically promote these programs based on tenure and position, this oversight appears to be particularly significant; calling for a reconsideration of design and target population in leadership development programs. Lacerenza, Reyes, Marlow, Joseph, \& Salas (2017) estimated the effectiveness of leadership training across four criteria (reactions, learning, transfer, and results) performing a metaanalysis to determine which elements are associated with the most effective leadership training interventions. Overall, their research suggested that leadership development interventions are indeed useful, showing the most significant effect for transfer (i.e. utilising the abilities that were taught), followed by learning (i.e. acquiring knowledge), results (i.e. achieving organisational objectives including costs, company profits, turnover and absenteeism) and reaction (i.e. trainee attitudes toward training).

\section{Leader self-development}

Little systematic research has been reported to advance the understanding of characteristics associated with individuals who initiate selfdevelopment activities to grow leadership skills (Boyce, Zaccaro, \& Wisecarver, 2010). Self-development leadership programs are a variant of leadership development where training focuses on learning experiences in which the leader takes primary responsibility for their growth in leadership capacities and where the leader essentially decides what knowledge, skills, and abilities they need to improve on and follow by choosing the most appropriate method (Kirchner \& Akdere, 2014). Boyce et al. (2010) claim that work, career-growth and mastery orientation of individuals are increasing the probability of leaders' self-development due to a higher level of motivation and higher skills at performing instructional and selfregulatory processes, but also that an organisational support tool can moderate the actual performance of leader self-development activities. But there are also indications that specific organisational-level (i.e., human resources practices) and group-level (i.e., supervisor style) constructs can promote leader self-development (Reichard \& Johnson, 2011). Collins \& Holton (2004) also outline the importance that the right development programs for the right people are offered at the right time.

\section{Self- and other-rating differences in leadership development initiatives utilizing 360-degree feedback measures}

In the process of leadership development, 360-degree feedback has become almost ubiquitous in organisations of every type and is an important step to facilitate development (Day et al., 2014). As one possible source of feedback, 360-degree ratings allow the participant in 
formulating comparisons among various rating sources, and provides the participant with a more holistic depiction of his or her areas for improvement because the results are not based on a single-source and therefore may be perceived as more reliable (Lacerenza et al., 2017). Abraham (2004), found that positive feedback delivered in an informative manner, can promote emotional honesty, self-confidence, and emotional resilience and superior performance. Today a consensus between practitioners and organisational consultants exists that solely selfratings are not sufficient for a valid evaluation of emotional intelligence capabilities and therefore recommend the use of 360-degree feedbacks as a system to enhance self-knowledge and improve managerial behaviour (Yammarino \& Atwater, 1997a; Sala, 2001; Wolff, 2005).

Yammarino and Atwater (1997) argue that the relative agreement or disagreement between self- and others rating has a potentially high impact on human resource management. It unveils information about personal characteristics, knowledge, skills, and abilities as well as training needs, performance appraisals or leadership behaviour. In the context of emotional intelligence, It is through the use of these multi-rater instruments and the discrepancies between self- and others-rating that one can get more insights into a leader interpersonal world (Brutus et al., 1999). Furthermore, the literature shows that self-perception can contribute to individual and organisational outcomes. Through the use of ratings generated by multi-rater instruments, the degree of agreement between self-perceptions and the perceptions of others can be employed to test this argument (Fleenor et al., 2010). Yammarino \& Atwater (1997a), argue that the two main reasons of different outcome of self- and other rating are that there is a general lack of feedback especially for individuals in higher ranks and that they, therefore, rely on their perception of themselves, and second that individuals might have a perception disorder or general difficulties to evaluate and compare themselves to others. In the field of emotional intelligence different theoretical developments also implied different methods for measuring these concepts. The question that arises when studying the academic literature is, whether leaders who are receiving feedback from peers, subordinates or their managers that deviates from their self-rating are more likely to see a need to take actions in their development compared to leaders were self- and other-ratings are very much alike. It is critical to understand whether high or low othersratings influence the reaction of the individual receiving the feedback (e.g., for enterprises that must establish their leadership development programs).

Brett \& Atwater (2001) researched how discrepancies in self-other feedbacks were related to reactions and receptivity to development as well as recipients' perceptions of usefulness and accuracy of the feedback. They found that less favourable ratings were related to beliefs that feedback 
was less accurate which also led to negative reactions. And because overestimators (leaders rating themselves higher than others) believe that their level of performance is already high, they may ignore developmental feedback and fail to improve their performance (Fleenor et al., 2010). It is agreed that emotional intelligent behaviour can be learned by those who are willing to learn and that continuous feedback from subordinates helps leaders to further develop their capabilities (Zakariasen \& ZakariasenVictoroff, 2012). It is the influence of a leaders' reactions to 360-degree feedback, that is determining whether they take actions to improve their performance or not, determining and showing their willingness to learn. For actual learning to occur, an individual must be motivated to learn and trainee reactions may serve as an indicator of motivation. Participants reactions reflect the attitudinal component of the effectiveness of leadership development programs and consist of trainee attitudes toward the training. They argue that given the popularity and importance of trainee reactions, it is critical to evaluate whether leadership training elicits positive changes in employee reactions (Lacerenza et al., 2017). Also, other scholars state that the reaction on others' feedback is influencing actions, but that this is a research field that has been neglected and deserves more research attention (Facteau et al., 1998). Brett and Atwater (2001) argue that if organisations want to retrieve their investment in leadership development programs "a better understanding of the emotional and cognitive reactions is needed" (p. 941). Therefore, organisations are confronted with the question, whether they have to take into account the fact that different outcomes of self- and others-rating affect the way their employees will react on their received feedback and additional intervention and support from the organisation will be needed. Since it is the primary goal of leadership development initiatives to change leaders' behaviours when performing their day-to-day tasks, it is essential to know what participants will actually do, after they received training and how they will utilise the skills and abilities that have been taught. The question, to what extent the different self-other rating groups influence these behavioural changes, arises.

Atwater and Yammarino (1992) introduced the idea to use rating agreement categories to analyse self and others' agreement data. This approach requires computing difference scores between self- and others' ratings and calculating the mean and standard deviation of the difference scores. Individuals are classified based on the extent of their selfothers' difference (i.e., the standard deviation from the mean self-others difference). Initially recommending three rating agreement categories Yammarino and Atwater (1997) extended their model to four categories.

Figure 1 shows the proposed categorisation into (a) Over Estimator (where the self-rating is higher as the others-rating), (b) In-Agreement/ Good (with a high self- and others-rating) (c) In-Agreement/Poor (a low 
self- and others-rating) and (d) Under Estimators (the self-rating is smaller than the others-rating).

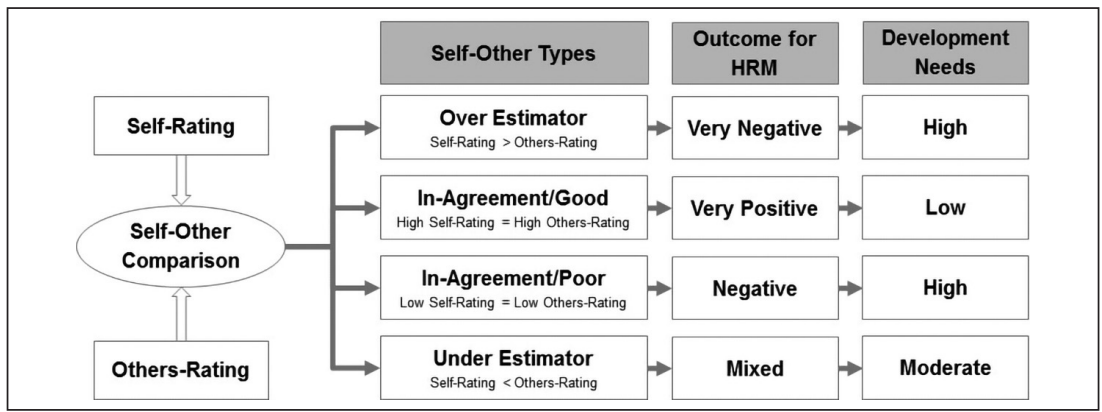

Source: Figure compiled by the author based on Yammarino and Atwater (1997) Do managers see themselves as others see them?

Figure 1: Differences in self- and others-rating

The case for positive development, after feedback has been given to participants, could be confirmed (Sala, 1999). But since it is not very resourceful to treat every individual the same, it is essential for organisations to know what differences in self-others ratings exist between the participants of leadership development programs. Studies support the fact that it is the kind of feedback that seems to influence how individuals are receiving feedback will react to the information provided (Facteau, 1998; Brett \& Atwater, 2001). In one study, Facteau et al. (1998) investigated factors that influence the perception of leaders when receiving 360-degree (i.e., multilevel) feedback. They found that managers' acceptance of subordinate feedback increased with increased favourableness of the feedback. Managers also tended to value the feedback as more useful, the higher their overall score according to their subordinates' ratings was.

\section{Methods}

The question to answer is whether participants of leadership development programs evaluated through 360-degree feedback see the value in this feedback to the extent that they are more likely to engage in developing their leadership capabilities. For actual learning to occur, an individual must be motivated to learn and trainee reactions may serve as an indicator of motivation (Lacerenza et al., 2017).

The underlying leadership development program in this study focussed on analysing managers emotional intelligence competencies, increasing their awareness on this topic and giving them an overview of how they rate 
themselves and how others rated them. To investigate, what the managers' approach to the feedback is, a questionnaire has been developed. This questionnaire has been sent to the managers a week after they received feedback about their self and other ratings of following the leadership development initiative. Fleenor et al. (2010) recommends to use simple indices such as comparisons of self-ratings to the mean ratings across rater groups, when giving 360-degree feedback to leaders and that in these situations, an overall index of rating agreement would be a useful indicator of whether an individual has a general tendency, for example, to under- or overestimate his or her performance.

It has been shown, that while there is an overlap between the acceptance and the perceived usefulness of others-feedback, these variables are not entirely redundant and therefore must be treated as separate dependent measures (Facteau et al., 1998). According to Fowler (1995), who defined characteristics for questions in questionnaires, it is important that all participants understand what the questions mean, that the questions are consistently administered and communicated to the respondents and that it is consistently communicated to all respondents what kind of answer is wanted. Further, it is necessary to make sure that all respondents had access to the information needed to answer the question and finally, respondents need to be willing to provide the answer demanded in the question. The developed questionnaire measures four components, (1) accuracy; (2) usefulness; (3) reaction to the feedback provided to the managers and (4) the likelihood to take development actions because of the feedback.

Accuracy measures the level to which managers feel that the received feedback truly reflects their competencies. The aim is to evaluate if recipients of feedback see the feedback as too positive or too negative. Facteau et al. (1998) for example used the term acceptance instead of accuracy to measure the "extent to which leaders believed that the feedback they received was an accurate representation of their performance" (p. 437). One example of a question measuring this part is: "I think that the feedback of my raters is very accurate regarding my competencies."

Usefulness as the second component of the model is examining the level to which the managers see the feedback to be useful for their development. Questions like "Due to the feedback I found areas that I can improve on" have been defined to measure this area.

The third area, likelihood to take personal development actions, is measuring the probability that managers that found development possibilities are taking steps to improve. This section is being evaluated with questions like "Due to the feedback, I think that I will work on areas where I can improve."

The questionnaire uses a 5-point Likert scale that ranges from 1 (very inaccurate) to 5 (very accurate) for the components "accuracy," "usefulness" and "likelihood to take personal development actions." 
How the managers react after receiving feedback is evaluated through the selection of a predefined mood. Positive (inspired, encouraged, informed, aware, pleased, motivated, enlightened), and negative (angry, judged, confused, examined, criticised, discouraged) emotions have been previously defined by Brett and Atwater (2001) and will be applied in the questionnaire. Scherer (2005) argued that individuals who have to describe their feelings often have problems to come up with appropriate labels and that difficulties can arise because of different vocabulary. He further states that participants might want to answer with a term or category that is not provided and therefore should take the next best alternative or a residual category like "other" and hence the accuracy of the data suffers (pp. 712). This is considered and thus the developed questionnaire will distinguish between positive and negative feelings but will also provide an open category for the participants where they can add describe other feelings. These feelings are then allocated to the rather positive or rather negative category. To ensure the understandability and to test the formulations, the questionnaire has been pre-tested. It has been given to managers in the human resource department and the questions have been discussed afterward. This led to certain changes in the formulation although the general understandability and unambiguity were confirmed.

The model for this research has been subsumed in Figure 2. The three components, type of reaction (being positive or negative), perceived accuracy of the feedback, and perceived usefulness of the feedback are the independent variables, the likelihood to take personal development actions is the dependent variable in the developed model. To analyse the research question and to test the hypothesis a survey has been created which has been delivered to managers immediately after they received feedback about their competencies which was evaluated through a 360-degree feedback process in a leadership development program. The increasing use of 360-degree feedback in organisations additionally led to the question, what influence differences in self- and other feedback have on the perceived accuracy and usefulness as well as on the likelihood that recipients of feedback take development actions on their own.

After conducting the preliminary literature review, it has been decided that quantitative, non-experimental, correlational design will be applied to answer the research question. This has been argued to be the best approach for the investigated problem because it enables the researcher to describe and measure the association or relationship between two or more variables or sets of scores using correlational statistics (Creswell, 2014). Also, Weathington, Cunningham, and Pittenger (2012) argue that correlational research is used to study the relationship between two or more variables and that it can be used to make predictions about the dependent variable using the independent variable. It is the method 
of "collecting information by asking a set of pre-formulated questions in a predetermined sequence in a structured questionnaire to a sample of individuals drawn to be representative of a defined population" that is known as survey research (Sreejesh et al., 2014, p. 58).

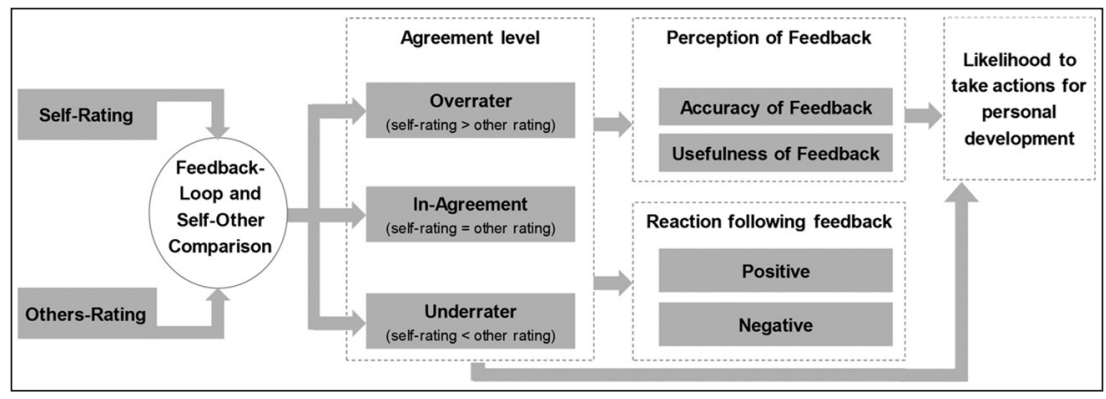

Source: Created by the author

Figure 2: Influence of rating differences on perceived usefulness, accuracy and likelihood to take personal development actions

Scholars argue that there is a significant probability, that if someone is participating in leadership development programs against their wishes, they will not fully engage in the themes being discussed (Kirchner \& Akdere, 2014). Therefore, together with the corporations' human resource department, every potential participant received information up-front and was personally asked to join the research study. It was explained, that every participant would receive personalised feedback regarding their emotional intelligence competencies, especially about the differences between their self-rating and the rating of others. Following, the data collection process was started.

The human resource department of the selected organisation was sending out an email to 95 managers that were all registered in their companies' internal leadership development program. There the intended study and the concept of emotional intelligence and the 360-degree feedback was explained. To be able to participate, managers had to be in their current position for a minimum of one year and had to have responsibility for at least three subordinates. The participants of the leadership development initiative were asked to self-rate their competencies and to name a minimum of two peers and two subordinates to provide feedback to them. In total, the managers nominated 204 raters. The questionnaire was completed by 28 managers $(87.5 \%)$ and 154 raters $(75.5 \%)$. All managers that had valid self- and others rating in received personalised feedback regarding their competencies with a clear differentiation between self- and other ratings. 
Two weeks after the feedback a link to a follow-up questionnaire was sent to those managers via e-mail. A total of 26 managers $(93 \%)$ responded with valid data providing data about their perception of the feedback and the likelihood that they will take personal development actions. These managers were grouped according to the level of agreement between their self- and other rating and their reaction, the perceived accuracy and usefulness as well as the likelihood to take individual development actions were analysed.

\section{Results and Discussion}

To investigate whether differences between the self-rating of managers and the rating they received from others exist, the mean average othersrating from peers and subordinates was compared to the self-ratings utilising the paired sample t-test for parametric independent variables. Spearman's rho was computed to find whether the parameters of perceived accuracy, usefulness and likelihood to take self-development actions, correlate. Following it was tested, utilizing the Kruskal-Wallis Test, whether the difference between self- and other ratings, shown in the three groups of overraters, underraters, and in agreement, also explain differences in the perceived accuracy of feedback, its usefulness and the likelihood that managers take future development actions on their own.

Following the recommendations of Shanock, Baran, Gentry, Pattison, \& Heggestad (2010) descriptive information about the occurrence of congruence and incongruence between self and others' ratings have been calculated to achieve a clearer initial understanding of the data. This has been done by standardising the score for self and other ratings. Leaders with a standardised score on the self-rating half a standard deviation above others' score were categorised as an over-estimator, whereas any leader with a standardised score for self-rating, half a standard deviation below others' score was categorised as an under-estimator. Leaders within these limits were categorised as in-agreement with others. As illustrated in Table 1, all three of the categories were well represented in the sample, which, according to Shanock et al. (2010), constituted a sound basis for the subsequent self-other analyses.

Table 1: Classification of groups according to rating differences

\begin{tabular}{lrrr} 
& N & Mean Self-Rating & Mean Other Rating \\
\hline In-Agreement & 9 & 3,91 & 3,90 \\
Overrater & 9 & 4,06 & 3,79 \\
Underrater & 8 & 3,75 & 4,12 \\
\hline
\end{tabular}

Note. $\mathrm{N}=26$.

Source: Created by the author, using own empirical data 
In Table 2 the descriptive statistics for the perceived accuracy and usefulness, as well as for the likelihood of managers to take individual development actions are shown. In the underlying questionnaire a 5 level Likert scale (ranging from 1-5) has been employed. The minimum and maximum values for accuracy range between 3 and 5, for usefulness and likelihood to take development actions between 2 and 5 . Due to the data, it can be stated that the participants perceived the development program particularly useful with a mean value of 4.04 . Although the mean values are lower for accuracy and likelihood for development, the mean values are still above average.

Table 2: Descriptive Statistics for accuracy and usefulness of feedback and the likelihood to take development actions

\begin{tabular}{|l|r|r|r|r|r|r|}
\hline & N & Minimum & Maximum & Mean & Std. Deviation & Variance \\
\hline Accuracy & 26 & 3,00 & 5,00 & 3,9038 &, 40048 &, 160 \\
Usefulness & 26 & 2,00 & 5,00 & 4,0423 &, 84719 &, 718 \\
Likelyhood for development & 26 & 2,00 & 5,00 & 3,6346 &, 79445 &, 631 \\
Valid N (listwise) & 26 & & & & & \\
\hline
\end{tabular}

Source: Created by the author, using own empirical data

Table 3 shows the Min, Max, Mean, Standard deviation and Variance of data for the self-other rating differences. The minimum and maximum are ranging from -.83 to .59 indicating the minimum and maximum values of the difference between self and other ratings. Negative values in this sample are occurring when the self-rating of managers is lower than the others rating (underraters). The standard deviation is .30 which is also used helping to distinguish the groups of managers being underraters, overraters or inagreement with their raters.

Table 3: Descriptive Statistics for self- and other rating differences

\begin{tabular}{|l|r|r|r|r|r|r|}
\hline & N & Minimum & Maximum & Mean & Std. Deviation & Variance \\
\hline Diff_Self_Other_Rating & 26 &,- 83 &, 59 &,- 0135 &, 30299 &, 092 \\
Valid N (listwise) & 26 & & & & & \\
\hline
\end{tabular}

Source: Created by the author, using own empirical data

After showing the descriptive statistics for the data of perceived accuracy, usefulness of feedback and the likelihood to take development actions, the three values were correlated to answer the research question. In Table 4 the three variables of perceived accuracy and usefulness, as well as likelihood to take development actions have been correlated 
using Spearman's rho. It can be noted that the perceived accuracy of the feedback that participants of leadership development programs get is also correlated with the perceived usefulness of this feedback $(p=.05)$. Furthermore, it is possible to see that perceived usefulness is statistically significantly correlated with individuals' likelihood to take development actions in the future on their own.

Table 4: Correlation between perceived accuracy, usefulness and likelihood to take development actions

\begin{tabular}{|c|c|c|c|c|c|}
\hline & & & Accuracy & Usefulness & $\begin{array}{r}\text { Likelyhood for } \\
\text { development }\end{array}$ \\
\hline \multirow[t]{9}{*}{ Spearman's tho } & \multirow[t]{3}{*}{ Accuracy } & Correlation Coefficient & 1,000 & $.422^{n}$ &, 224 \\
\hline & & Sig. (2-tailed) & & .032 & ,272 \\
\hline & & $\mathrm{N}$ & 26 & 26 & 26 \\
\hline & \multirow[t]{3}{*}{ Usefulness } & Correlation Coefficient & $.422^{x}$ & 1,000 & $.547^{m 11}$ \\
\hline & & Sig. (2-tailed) &, 032 & &, 004 \\
\hline & & N & 26 & 26 & 26 \\
\hline & \multirow{3}{*}{$\begin{array}{l}\text { Likelyhood for } \\
\text { development }\end{array}$} & Correlation Coefficient & .224 & $.547^{n 1}$ & 1,000 \\
\hline & & Sig. (2-tailed) & .272 &, 004 & \\
\hline & & $\mathrm{N}$ & 26 & 26 & 26 \\
\hline
\end{tabular}

*. Correlation is significant at the 0.05 level (2-tailed).

${ }^{\star \star}$. Correlation is significant at the 0.01 level (2-tailed).

Source: Created by the author, using own empirical data

\section{Influence of rating group difference on the perceived accuracy and usefulness of feedback and the likelihood to take development actions}

Through the literature research it was possible to understand that despite the vast amount and effort that is put on leadership development, many of these development programs fail. Research suggests that the lack of feedback plays an essential part in this phenomenon. The 360-degree feedback is one of the most prominent ways to get leadership development program participants own view and the view of others about the person's capabilities. But what research also shows, is that after the feedback has been provided to the participant, in many cases the participant is left alone with the outcome. This part of the study aims to give insight on how individuals react on feedback and whether differences in rating outcome between the self and other ratings can influence the participants' initiatives for their development. In Table 5 the mean ranks for the groups of overraters, underraters and in agreement participants for accuracy, usefulness and the likelihood for development actions are displayed. Further, the Kruskal Wallis Test is shown. 
Table 5: Influence of self- and other rating differences on perceived accuracy, usefulness, and likelihood for development actions

\begin{tabular}{|c|c|c|c|}
\hline & Over_Under_InAgreement & $\mathrm{N}$ & Mean Rank \\
\hline \multirow[t]{4}{*}{ Accuracy } & 1 & 9 & 14,06 \\
\hline & 2 & 9 & 13,28 \\
\hline & 3 & 8 & 13,13 \\
\hline & Total & 26 & \\
\hline \multirow[t]{4}{*}{ Usefulness } & 1 & 9 & 13,33 \\
\hline & 2 & 9 & 17,22 \\
\hline & 3 & 8 & 9,50 \\
\hline & Total & 26 & \\
\hline \multirow[t]{4}{*}{ Likelyhood for development } & 1 & 9 & 16,22 \\
\hline & 2 & 9 & 13,89 \\
\hline & 3 & 8 & 10,00 \\
\hline & Total & 26 & \\
\hline
\end{tabular}

\begin{tabular}{|l|r|r|r|}
\hline & Accuracy & Usefulness & $\begin{array}{r}\text { Likelihood for } \\
\text { development }\end{array}$ \\
\hline Chi-Square &, 094 & 4,441 & 3,037 \\
df & 2 & 2 & 2 \\
Asymp. Sig. &, 954 &, 109 &, 219 \\
Exact Sig. &, 958 &, 108 &, 222 \\
Point Probability &, 005 &, 000 &, 001 \\
\hline
\end{tabular}

a. Kruskal Wallis Test

b. Grouping Variable: Over_Under_InAgreement

Source: Created by the author, using own empirical data

Reviewing the results, it can be stated that with a significance level of .954 for accuracy, .109 for usefulness and .219 for the likelihood to take development actions the three groups of self-other rating comparison (Overrater, Underrater, InAgreement) do not differ significantly which indicates that rating group differences have no effect on the three dependent variables.

\section{Conclusion and Discussion}

Several studies support the statement that there is a significant difference between self and other ratings in leadership development programs that use 360-degree feedback. The empirical data in this study confirmed this statement, showing the difference between managers self and other ratings. Contrary, there was no evidence that those differences between self- and other-ratings influence the likelihood for participants to 
take self-development actions. Additionally, the difference did not influence how accurate or useful participants perceived the feedback to be.

The statement that the perceived accuracy and usefulness of feedback also leads to an increased likelihood to take personal development actions was partly supported. On the one side, perceived accuracy of the feedback did not correlate with the likelihood to take development actions, on the other side, the more useful participants perceived the feedback, the more likely participants were about to engage in further personal development actions. Investing in leadership development programs can pay off. Research has shown that organisational interventions in leadership development are less successful than stimulating individuals to take their development into their own hands. Nevertheless, still, many corporations do not encourage employees to increase their leadership capabilities. Data gathered in this study suggest that it is essential for individuals to see the leadership development programs as being useful for them to further engage in their self-development following an initiative that was introduced by their company. Only this will secure a sustainable and continuous improvement of the management and leadership force. Often participants are left alone with their feedback results and there is a need for a specific strategy following 360-degree feedback taking into consideration that employees react differently on feedback and that some need more encouragement than others to develop their skills further. As research was showing, the perceived usefulness is correlating with the likelihood to take personal development actions, initiators of leadership development programs have to make sure that they explain how participants can benefit from the training, possibly also providing examples from workplace situations where participants can understand the value of the planned leadership development initiative.

\section{REFERENCES}

Abraham, R. (2004), Emotional competence as antecedent to performance: a contingency framework. Genetic, Social, and General Psychology Monographs, 130(2), 117-143. https://doi.org/10.3200/MONO.130.2.117-145

Arnulf, J. K., Glasø, L., Andreassen, A. K. B., \& Martinsen, Ø. L. (2016), The dark side of leadership development: An exploration of the possible downsides of leadership development. Scandinavian Psychologist, 3(18), 1-21. https://doi.org/10.15714/ scandpsychol.3.e18

Atwater, L. E., \& Yammarino, F. J. (1992), Does self-other agreement on leadership perceptions moderate the validity of leadership and performance predictions? Personnel Psychology, 45(1), 141-164. https://doi.org/10.1111/j.1744-6570.1992. tb00848.x 
Avolio, B. J., Avey, J. B., \& Quisenberry, D. (2010), Estimating return on leadership development investment. Leadership Quarterly, 21(4), 633-644. https://doi.org/ https://doi.org/10.1016/j.leaqua.2010.06.006

Boyce, L. A., Zaccaro, S. J., \& Wisecarver, M. Z. (2010), Propensity for self-development of leadership attributes: Understanding, predicting, and supporting performance of leader self-development. Leadership Quarterly, 21(1), 159-178. https:/doi.org/ 10.1016/j.leaqua.2009.10.012

Brett, J. F., \& Atwater, L. E. (2001), 360 degree feedback: accuracy, reactions, and perceptions of usefulness. The Journal of Applied Psychology, 86(5), 930-942. https:// doi.org/10.1037/0021-9010.86.5.930

Brungardt, C. (1997), The Making of Leaders: A Review of the Research in Leadership Development and Education.Journal ofLeadership Studies, 3(3), 81-95. https://doi.org/ 10.1177/107179199700300309

Brutus, S., Fleenor, J., \& Tisak, J. (1999), Exploring the link between rating congruence and managerial effectiveness. Canadian Journal of Administrative Sciences, 16(4), 308-322. https://doi.org/10.1111/j.1936-4490.1999.tb00691.x

Burke, M. J., \& Day, R. R. (1986), A cumulative study of the effectiveness of managerial training. Journal of Applied Psychology, 71(2), 232-245. https://doi.org/ 10.1037/0021-9010.71.2.232

Collins, D. B., \& Holton, E. F. (2004), The Effectiveness of Managerial Leadership Development Programs: A Meta-Analysis of Studies from 1982 to 2001. Human Resource Development Quarterly, 15(2), 217-248. https://doi.org/10.1002/hrdq.1099

Creswell, J. W. (2014), Research design: qualitative, quantitative, and mixed methods approaches ( $4^{\text {th }}$ ed.). Thousand Oaks, CA: SAGE Publications, Inc.

Day, D. V., Fleenor, J. W., Atwater, L. E., Sturm, R. E., \& McKee, R. A. (2014), Advances in leader and leadership development: A review of 25 years of research and theory. The Leadership Quarterly, 25(1), 63-82. https://doi.org/10.1016/j. leaqua.2013.11.004

Ely, K., Boyce, L. A., Nelson, J. K., Zaccaro, S. J., Hernez-Broome, G., \& Whyman, W. (2010), Evaluating leadership coaching: A review and integrated framework. Leadership Quarterly, 21(4), 585-599. https://doi.org/10.1016/j.leaqua.2010.06.003

Facteau, C. L., Facteau, J. D., Schoel, L. C., Russell, J. E. a., \& Poteet, M. L. (1998), Reactions of leaders to 360-degree feedback from subordinates and peers. The Leadership Quarterly, 9(4), 427-448. https://doi.org/10.1016/S1048-9843(98)90010-8

Fleenor, J. W., Smither, J. W., Atwater, L. E., Braddy, P. W., \& Sturm, R. E. (2010), Selfother rating agreement in leadership: A review. Leadership Quarterly, 21(6), 10051034. https://doi.org/10.1016/j.leaqua.2010.10.006

Fowler, F. J. (1995), Improving Survey Questions: Design and Evaluation. Thousand Oaks, CA: SAGE Publications, Inc.

Goethals, G. R., Sorenson, G. J., \& Burns, J. M. (Eds.) (2004), Encyclopedia of Leadership ( $1^{\text {st }}$ ed.). Thousand Oaks, CA: SAGE Publications.

Gurdjian, P., Halbeisen, T., \& Lane, K. (2014), Why leadership-development programs fail. McKinskey Quarterly, 1(1), 121-126. 
Kirchner, M. J., \& Akdere, M. (2014), Leadership Development Programs: An Integrated Review Of Literature. Journal of the Knowledge Economy, 9(1), 137-146.

Krims, J. (2016), Leadership Development - Entscheidende Faktoren für die Entwicklung von Führungskräften. Deloite Austria.

Lacerenza, C. N., Reyes, D. L., Marlow, S. L., Joseph, D. L., \& Salas, E. (2017), Leadership Training Design, Delivery, and Implementation: A Meta-Analysis. Journal of Applied Psychology, 1-33. https://doi.org/10.1037/apl0000241

PWC (2016), Redefining business success in a changing world. $19^{\text {th }}$ Annual Global CEO Survey. Retrieved from http://www.pwc.com/gx/en/ceo-survey/2016/landing-page/ pwc-19th-annual-global-ceo-survey.pdf

Reichard, R. J., \& Johnson, S. K. (2011), Leader self-development as organizational strategy. Leadership Quarterly, 22(1), 33-42. https://doi.org/10.1016/j.leaqua.2010.12.005

Sala, F. (1999), Do Programs Designed to Increase Emotional Intelligence at Work Work? Consortium for Research on Emotional Intelligence in Organizations, 1-6.

Sala, F. (2001), It's lonely at the top: executives' emotional intelligence self [mis] perceptions. Consortium for Research on Emotional Intelligence in Organizations, 1-10. Retrieved from http://www.eiconsortium.org/research/executive_emotional_ intelligence360.htm.

Scherer, K. R. (2005), What are emotions? And how can they be measured? Social Science Information, 44(4), 695-729. https://doi.org/10.1177/0539018405058216

Sreejesh, S., Mohapatra, S., \& Anusree, M. R. (2014), Business Research Methods. Cham: Springer International Publishing. https://doi.org/10.1007/978-3-319-00539-3

Van Velsor, E., McCauley, C. D., \& Ruderman, M. N. (2010), The Center for Creative Leadership Handbook of Leadership Development. (E. Van Velsor, C. D. McCauley, \& M. N. Ruderman, Eds.), JB CCL Center for Creative Leadership ( $3^{\text {rd }}$ ed., Vol. 1). San Francisco, CA: John Wiley \& Sons, Inc.

Weathington, B. L., Cunningham, C. J. L., \& Pittenger, D. J. (2012), Understanding Business Research. Hoboken, NJ, USA: John Wiley \& Sons, Inc.

Wolff, S. B. (2005), The Emotional Competence Inventory (ECI) - Technical Manual. Retrieved from http://doi.apa.org/psycinfo/2004-19636-007

Yammarino, F.J., \& Atwater, L. (1997a), Do managers see themselves as other see them? Implications of self-other rating agreement for human resources management, 35-44.

Yammarino, F. J., \& Atwater, L. E. (1997b), Do managers see themselves as other see them? Implications of self-other rating agreement for human resources management. Organizational Dynamics, 25(4), 35-44.

Zakariasen, K., \& Zakariasen-Victoroff, K. (2012), Leaders and emotional intelligence: A view from those who follow. Healthcare Management Forum, 25(2), 86-90. https:// doi.org/10.1016/j.hcmf.2012.05.006 